\title{
The Analysis of Problem-Solving Skills and Related Factors for Some Students Studying at Different Schools of Physical Education and Sports
}

\author{
Bekir Barış CIHAN ${ }^{1}$ \\ 'University of Yozgat Bozok, School of Physical Education and Sports, Tozgat, Turkey \\ Email:baris.cihan@bozok.edu.tr Tel: 5052482279
}

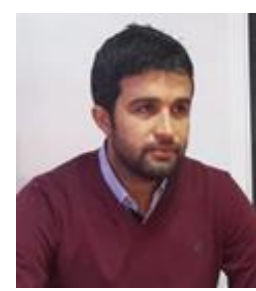

\begin{abstract}
People face many different small or great problems in certain periods of their lives. The most distinct quality of problem-solving skills is to eliminate all negative phenomena in order to achieve a certain goal. This study aims to understand whether problem-solving skills of some students studying at the departments of physical education teaching, coaching education and sports management at different schools of physical education and sports vary depending on their university, department, gender, and socio-economic status. 243 female and 351 male students $(\mathrm{N}=594)$ studying at School of Physical Education and Sports at the University of The Yozgat Bozok, Erciyes University and Omer Halis Demir University during 2017-2018 academic year comprise the sample of the present study. To this aims, Problem-Solving Inventory (PSI), which was developed by Heppner and Petersen (1982) and adapted by Sahin et al. (1993) was used as a data collection tool. Data normality was tested using Kolmogorov-Smirnov and Shapiro-Wilks tests. T-test and One-Way Analysis of Variance (ANOVA) were also applied to independent samples to test hypotheses. When the number of independent variable groups was more than one and ANOVA results were significant, post-hoc LSD test was applied in order to identify differences between groups. The data analysis demonstrated that female students' problemsolving skills were significantly higher compared to male students. In addition, the participants' average problem-solving skill scores displayed a significant difference. It was found out that average problem-solving skill scores of students studying at the University of Yozgat Bozok were significantly higher than those studying at Erciyes University and Omer Halis Demir University.
\end{abstract}

Keywords: Problem, Skill, Teacher, Coaching, Sports.

Citation | Bekir Barış CIHHAN (2018). The Analysis of ProblemSolving Skills and Related Factors for Some Students Studying at Different Schools of Physical Education and Sports. Asian Journal of Education and Training, 4(4): 295-301.

History:

Received: 16 July 2018

Revised: 10 August 2018

Accepted: 16 August 2018

Published: 20 August 9018

Licensed: This work is licensed under a Creative Commons

Attribution 3.0 License (c) $)$

Publisher:Asian Online Journal Publishing Group

\section{Contents}

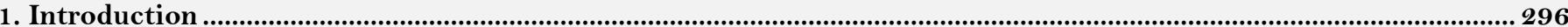

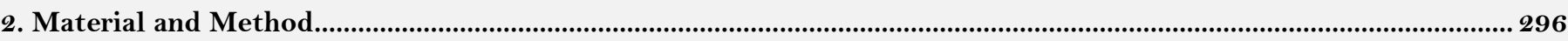

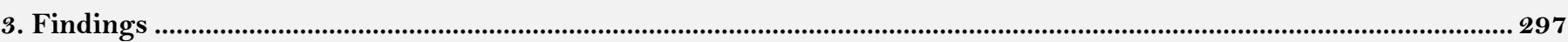

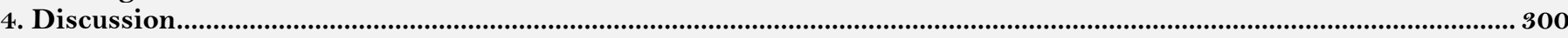

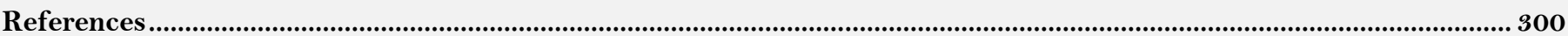




\section{Introduction}

An individual will always encounter problems in different amounts and quality throughout their lifetime, and their problem-solving methods will vary depending on their intelligence, experience and character. It is not possible to live a life without any problems. Therefore, instead of expecting a problem-free life, it is of vital importance to learn various techniques for overcoming problems as problem-solving skills directly influence an individual's life quality.

Korkut (2002) defines problem-solving as repeating certain experienced behaviours as well as offering alternative strategies. In addition to cognitive skills, problem-solving is a complex concept that addresses emotional, behavioral and social skills. Additionally, problem-solving is closely related to an individual's psychological well-being, self-confidence, sufficient communication skills and decision-making.

Ulger (2003) defines problem-solving as making right moves for the solution and offering satisfactory and analytic solutions to complex situations. In this respect, an individual must gain skills that will help them obtain positive results, and problem-solving must become a regular behavior.

Ferah (2000) states that an individual's self-confidence is positively influenced by their ability to solve problems and that this enables them to solve their problems in a more courageous, determined and bolder manner. As a result, positive and satisfactory results encourage them to approach their future more optimistically.

According to Soylemez (2002), personal traits that today's students need to bear are high social communication skills, scientific, logical and cognitive thinking skills, a satisfactory level of technological knowledge and humanitarian values.

An individual with a high level of problem-solving skills will definitely attempt to raise their children with a high problem-solving success, which is strongly associated with that individual's ability to overcome his/her own problems (Güçlü, 2003). People with high problem-solving skills can also be considered as positive, confident, bold and self-criticizing individuals who take responsibility and always come up with new ideas. University education occupies a critical position in an individual's life and character. In this period, an individual experiences different physical, mental, emotional and social states. At the beginning of their education, university students try to adapt to a new city and social environment/circle/group and separate from his family for the first time in their life, which leads to various problems. Therefore, they need to gain skills for analyzing their problems, offering creative solutions to these problems and realizing their skills in real-life situations.

A school of physical education and sports and a faculty of sports sciences are 4-year educational institutions where sports are analyzed from a scientific perspective. These institutions offer a formal education at the departments of physical education and sports teaching, sports management, coaching education and recreation. Sports management aims to train students and provide them with sport-related skills in the fields of communication, business administration, and finance. In addition, it is aimed to train administrators which will manage and lead a certain group thanks to their leadership skills in the field of sports.

Coaching education entails formal education related to physical movement and training. These schools train technical officers, coaches, analysis expert, masseurs and fitness trainers. Finally, physical education and sports teaching department aims to train teacher candidates with a high physical, emotional and psychological capacity and who can apply their knowledge in the most efficient ways.

A teacher, coach, and sports manager with a high level of problem-solving skills should be trained so as to possess suitable skills that will increase their colleagues' and students' living conditions. This can only be achieved by a well-prepared physical education and sports curricula which take all dimensions of human development into account, satisfy modern requirements, and identify and offer solutions to students' problems.

This study aims to compare and identify problem-solving skills of students studying at different departments of the school of physical education and sports and analyze these data using different variables.

\section{Material and Method \\ 2.1. Study Group}

A cross-sectional research design was used in this study. The study group is comprised of 594 students who were selected based on convenience sampling and study at different sports departments of three different universities in the Central Anatolian region of Turkey. Inconvenience sampling method, researchers select their sample by taking various factors into consideration such as cost, time and sample accessibility (Cohen et al., 2007). 334 male $(59 \%)$ and 228 female students (\%41) participated in the study. Participants' age varies between 18 and 35 , and their average years of age is 20.55 (S.D: 2.16). While 185 (\%32.9) students study physical education and sports teaching, $233(41.5 \%)$ and 144 students (25.6\%) study coaching education and sports management, respectively.

\subsection{Data Collection Tools}

Personal Information Form: This form was developed in order to gain information concerning participants' socio-demographic features. It can be used to identify participants' gender, age, university, family, location/residence, department, socio-economic status, sports branch, and coaching/referee license.

Problem Solving Inventory (PSI): Developed by Heppner and Petersen (1982) PSI is generally used to analyze participants' problem-solving capacity, skills, and style as well as their awareness. Different researchers have so far adapted PSI to Turkish context and tested its validity and reliability (Taylan, 1990; Sahin et al., 1993; Cam, 1995). The present study benefits from PSI adapted by Sahin et al. (1993). Findings on the construct validity of this scale indicate that it consists of six sub-dimensions as impulsive, reflective, avoidant, monitoring, confident and the planful styles (Sahin et al., 1993). Its known-group validity demonstrated that total PSI scores of non-depressed and non-anxious groups were significantly lower compared to depressed and anxious groups (Sahin et al., 1993). In other words, it was observed that individuals with a lower level of depression and anxiety had significantly higher problem-solving skills. Convergent and discriminant validity of the scale indicates that total PSI scores display a moderate positive significant correlation with depression $(r=.33)$ and anxiety $(r=.45)$, which means that individuals with a lower level of problem-solving skills had a higher level of depression and anxiety (Sahin et al., 
1993). Validity findings of the scale demonstrate that its Cronbach alpha internal consistency coefficient in a sample consisting of university students was .88 (Sahin et al., 1993). PSI can be employed for its sub-dimensions or measuring total scores. Because this study aims to measure participants' general problem-solving skills, PSI was used to assess total scores. PSI is a six-point Likert-type scale consisting of 32 items. Participants choose one of the statements ranging from "I always behave like this" (1) to "I never behave like this" (6) in order to state the suitability of each scale item for them. 14 items are reverse coded in the scale. Reverse coded items are re-coded before total scores are calculated, and participants can reach a total score of 32 to 192. A lower score points to more functional and effective problem-solving skills. A sample item from PSI is as follows: "I can usually offer creative and effective solutions to my problems". Cronbach alpha internal consistency coefficient of PSI for this study was calculated as .88 .

\subsection{Procedure}

The data were collected from students who studied at schools of physical education and sports at three different universities in the academic year 2017-2018. Before surveys were conducted, participants were informed about voluntary participation in the study and optional withdrawal from the study at any time, and they were ensured that their answers would remain anonymous and be only used in parallel with the aim of this study. In addition, all participants were asked to sign a written consent form prior to the survey. None of the students refused to participate in the study. Surveys lasted nearly 20 minutes.

\subsection{Data Analysis}

All data were statistically analyzed using SPSS 23 program. As Tabachnick and Fidell (2012) suggest, a preliminary analysis was performed prior to the data analysis. Data accuracy, missing data, outliers, and statistical analysis assumptions were investigated at the beginning. Minimum and maximum values in the data set were analyzed in order to test data accuracy, and it was found out that all variables were within expected value ranges. No missing data were found in the data set. Participants' PSI scores were standardized and converted to z-scores in order to detect univariate outliers and, as Tabachnick and Fidell (2012) suggests, two participants whose z scores were between -3.29 and + 3.29 were omitted from the data set. T-test and One-Way Analysis of Variance (ANOVA) were also applied to independent samples to test hypotheses. When the number of independent variable groups was more than one and ANOVA results were significant, post-hoc LSD test was applied in order to identify differences between groups. The reason why this post hoc test was used is that it had a higher statistical strength and a much lower Type I error rate compared to other post hoc tests (e.g. Scheffe, Tukey HSD) when the number of groups was three (Hayter, 1986; Levin et al., 1994).

T-test and ANOVA can be used to statistically test independent samples in terms of normality and variance homogeneity assumptions (Ho, 2013; Green and Salkind, 2014; George and Mallery, 2016; Pituch and Stevens, 2016). Skewness and kurtosis values of PSI scores for each independent variable category was analyzed to assess the normality assumption. As a general rule, a skewness and kurtosis value varying between -2 and +2 indicate a near-normal data distribution (Field, 2013; George and Mallery, 2016; Pituch and Stevens, 2016). It was observed in the data that skewness and kurtosis values of PSI in all categories were within this range. In this respect, it can be stated that the data display a near-normal distribution. Levene test, which analyzes changes independent variables in the sub-categories (groups) of the independent variable, was used to test the variance homogeneity assumption. The Levene test results indicate that the data did not violate variance analysis homogeneity assumption. Recommended if variance homogeneity is violated, Welch F testy (Howell, 2013) was also used to test the difference between average group values, and the same results were obtained. As a result, ANOVA results were reported in the Findings section.

The data analysis was reported along with effect size estimations. While Cohen's d is the most widely used effect size to measure the effect size of the difference between average values of two groups, eta-squared ( $\eta 2$ ) effect size is often used in ANOVA when the group number is higher than two. The effect size classification proposed by Cohen (1992) divided values into three groups as a small effect, i.e. lower than .20, medium effect, i.e. nearly .50, and large effect, i.e. higher than .80. As for eta-squared values, .01, .06 and 14 are classified as a small, medium and large effect, respectively. Type I error rate was taken as .05 in all analysis.

\section{Findings}

In this section, descriptive statistics of the students participating in this study are given, and later hypotheses are tested. Participants' socio-demographic features are given in Table 1.

As shown in Table 1, most of the participants (59.1\%) are male and study at University of Yozgat Bozok (39.9\%). While a large part of the participants lives with a housemate (35.2\%), a small part of them (11.1\%) spent most of their lives in a town or village. While a large part of the participants (41.2\%) study coaching education, most of them state that the economic status of their family is average $(77.9 \%)$. While most of the participants $(49.2 \%)$ are engaged in team sports, only a very small part of them do not have a sibling (6.9\%). Finally, a large part of the participants does not possess a coaching or referee license. 
Table-1. Students' descriptive statistics

\begin{tabular}{|c|c|c|}
\hline \multirow[b]{2}{*}{ Variable } & \multirow[b]{2}{*}{$\mathbf{n}$} & \\
\hline & & $\%$ \\
\hline \multicolumn{3}{|l|}{ Gender } \\
\hline Male & 351 & 59.1 \\
\hline Female & 243 & 40.9 \\
\hline \multicolumn{3}{|l|}{ University } \\
\hline Yozgat Bozok & 237 & 39.9 \\
\hline Erciyes & 198 & 33.3 \\
\hline Omer Halis Demir & 159 & 26.8 \\
\hline \multicolumn{3}{|l|}{ Residence } \\
\hline Living with my family & 197 & 33.2 \\
\hline Living with a housemate & 209 & 35.2 \\
\hline At dormitory & 188 & 31.6 \\
\hline \multicolumn{3}{|l|}{ Location } \\
\hline Province & 411 & 69.2 \\
\hline City & 117 & 19.7 \\
\hline Village/Town & 66 & 11.1 \\
\hline \multicolumn{3}{|l|}{ Department } \\
\hline Teaching & 194 & 32.7 \\
\hline Coaching & 245 & 41.2 \\
\hline Management & 155 & 26.1 \\
\hline \multicolumn{3}{|l|}{ Economic Status } \\
\hline Low & 80 & 13.5 \\
\hline Moderate & 463 & 77.9 \\
\hline High & 51 & 8.6 \\
\hline \multicolumn{3}{|l|}{ Sports Branch } \\
\hline Individual & 232 & 39.0 \\
\hline Team Sports & 292 & 49.2 \\
\hline No Branch & 70 & 11.8 \\
\hline \multicolumn{3}{|l|}{ Siblings } \\
\hline No siblings & 41 & 6.9 \\
\hline I have sibling(s) & 553 & 93.1 \\
\hline \multicolumn{3}{|l|}{ Coaching License } \\
\hline Yes & 216 & 36.4 \\
\hline No & 378 & 63.6 \\
\hline
\end{tabular}

Tablo-2. T-test results of independent samples in terms of gender

\begin{tabular}{l|l|l|l|l|l|l}
\hline & M & SD & df & t & p & Cohen's d \\
\hline Male & 98.76 & 18.06 & 592 & 3.14 & $.002^{* *}$ & .26 \\
\hline Female & 93.89 & 19.23 & & & & \\
\hline$p<.05^{*}, p<.01^{* *}$ &
\end{tabular}

Average problem-solving skill scores, standard deviations and t-test results in terms of independent samples for both genders are given in Table 2 . This table demonstrates that females students' problem-solving skills are significantly higher than males $(t(592)=3.12, p<.01$, Cohen's $d=.26)$. However, this difference has a low effect size.

Tablo-3. ANOVA results in terms of universities where participants study

\begin{tabular}{l|l|l|l|l|l|l|l}
\hline & $\mathbf{M}$ & $\mathbf{S D}$ & $\mathbf{d f}_{1}, \mathbf{d f}_{2}$ & $\mathbf{F}$ & $\mathbf{p}$ & $\boldsymbol{\eta}^{2}$ & Post-hoc \\
\hline 1. Bozok & $93.52_{\mathrm{b}}$ & 18.86 & 2,591 & 6.28 & $.002^{* *}$ & .02 & $1-2,1-3$ \\
\hline 2. Erciyes & $98.34_{\mathrm{a}}$ & 17.69 & & & & & \\
\hline 3.Ömer Halis Demir & $99.64_{\mathrm{a}}$ & 19.01 & & & & & \\
\hline$p<.05^{*}, p<.01^{* *}, \mathrm{a}>\mathrm{b}$. &
\end{tabular}

Average problem-solving skill scores, standard deviations, and ANOVA results in terms of universities where participants study are given in Table 3 . This table demonstrates that participants' universities display a significant difference in terms of their average problem-solving skill scores $\left(F(2,591)=6.28, p<.01, \eta^{2}=.02\right)$. However, these differences have a low effect size. Post-hoc LSD tests indicate that problem-solving skills of students studying at University of Yozgat Bozok $(M=93.52)$ were significantly higher compared to those studying at Erciyes University $(M=98.34)$ and Omer Halis Demir University $(M=99.64)$. No significant differences were observed among other groups.

Table-4. ANOVA results in terms of residence

\begin{tabular}{l|l|l|l|l|l|l|l}
\hline & $\mathbf{M}$ & $\mathbf{S D}$ & $\mathbf{d f}_{1}, \mathbf{d f}_{\mathbf{2}}$ & $\mathbf{F}$ & $\mathbf{p}$ & $\boldsymbol{\eta}^{\mathbf{2}}$ & Post-hoc \\
\hline 1. Living with my family & $98.06_{\mathrm{a}}$ & 18.12 & 2,591 & 13.77 & $.001^{*} *$ & .05 & $1-3,2-3$ \\
\hline 2. Living with my friends & $100.57_{\mathrm{a}}$ & 18.12 & & & & & \\
\hline 3.At dormitory & $91.18_{\mathrm{b}}$ & 18.67 & & & & & \\
\hline$p<.05^{*}, p<.01^{* *}, \mathrm{a}>\mathrm{b}$. &
\end{tabular}

Average problem-solving skill scores, standard deviations and ANOVA results in terms of participants' residences are given in Table 4. This table demonstrates that participants' residences display a significant difference in terms of their average problem-solving skill scores $\left(F(2,591)=13.77, p<.001, \eta^{2}=.05\right)$. However, these differences have a low effect size. Post-hoc LSD tests indicate that problem-solving skills of students living at 
dormitory $(M=91.18)$ were significantly higher compared to those living with their family $(M=98.06)$ and living with a housemate $(M=100.57)$. No significant differences were observed among other groups.

Tablo-5. ANOVA results in terms of the location where participants spent most of their lives

\begin{tabular}{|c|c|c|c|c|c|c|}
\hline & $\overline{\mathbf{M}}$ & SD & $\overline{d f_{1}, d f f_{2}}$ & $\mathbf{F}$ & $\bar{p}$ & $\overline{\eta^{2}}$ \\
\hline 1. Province & 97.57 & 18.65 & 2,591 & 1.31 & .271 & .00 \\
\hline 2. City & 95.33 & 17.36 & & & & \\
\hline 3. Village/Town & 94.29 & 21.00 & & & & \\
\hline
\end{tabular}

Average problem-solving skill scores, standard deviations and ANOVA results in terms of locations where participants spent most of their lives are given in Table 5. This table demonstrates that no significant differences were observed among participants' average problem-solving skill scores in terms of locations where they have spent most of their lives $\left(F(2.591)=1.31, p>.05, \eta^{2}=.00\right)$.

Table-6. ANOVA results in terms of departments at which participants study

\begin{tabular}{l|l|l|l|l|l|l}
\hline & $\mathbf{M}$ & $\mathbf{S D}$ & $\mathbf{d f _ { 1 } , \mathbf { d f } _ { 2 }}$ & $\mathbf{F}$ & $\mathbf{p}$ & $\boldsymbol{\eta}^{2}$ \\
\hline 1. Teaching & 95.74 & 19.34 & 2,591 & 1.80 & .166 & .01 \\
\hline 2. Coaching & 98.49 & 17.58 & & & & \\
\hline 3. Management & 95.32 & 19.44 & & & & \\
\hline$p<.05^{*}, p<.01^{* * *}$
\end{tabular}

Average problem-solving skill scores, standard deviations, and ANOVA results in terms of departments at which participants study are given in Table 6. This table demonstrates that no significant differences were observed among participants' average problem-solving skill scores in terms of departments at which they study $\left(F(2,591)=1.80, p>.05, \eta^{2}=.01\right)$.

Table-7. ANOVA results in terms of participants' perceived economic status

\begin{tabular}{l|l|l|l|l|l|l}
\multicolumn{7}{l}{ Table-7. ANOVA results in terms of participants' perceived economic status } \\
\hline & $\mathbf{M}$ & SD & $\mathbf{d f}_{1}, \mathbf{d f}_{2}$ & $\mathbf{F}$ & $\mathbf{p}$ & $\mathbf{\eta}^{2}$ \\
\hline 1. Low & 92.99 & 19.19 & 2,591 & 2.01 & .135 & .01 \\
\hline 2. Moderate & 97.48 & 18.48 & & & & \\
\hline 3. High & 96.18 & 19.45 & & & & \\
\hline$p<.05^{*}, p<.01^{* * *}$ &
\end{tabular}

Average problem-solving skill scores, standard deviations and ANOVA results in terms of participants' perceived economic status are given in Table 7 . This table demonstrates that no significant differences were observed among participants' problem-solving skill scores in terms of their perceived economic status $(F(2,591)=$ $\left.2.01, p>.05, \eta^{2}=.01\right)$.

Table-8. ANOVA results in terms of participants' sports branches

\begin{tabular}{|c|c|c|c|c|c|c|}
\hline & $\mathbf{M}$ & SD & $\mathbf{d f}_{1}, \mathbf{d f}_{2}$ & $\mathbf{F}$ & p & $\eta^{2}$ \\
\hline 1. Individual & 98.65 & 17.82 & 2,591 & 2.31 & .100 & .01 \\
\hline 2. Team & 95.97 & 19.59 & & & & \\
\hline 3. No branch & 93.84 & 17.25 & & & & \\
\hline
\end{tabular}

Average problem-solving skill scores, standard deviations and ANOVA results in terms of participants' sports branches are given in Table 8 . This table demonstrates that no significant differences were observed among participants' problem-solving skill scores in terms of their sports branches $\left(F(2,591)=2.31, p>.05, \eta^{2}=.01\right)$.

Table-9. T-test results of independent samples in terms of number of siblings

\begin{tabular}{l|l|l|l|l|l|l}
\hline & M & SD & df & t & p & Cohen's d \\
\hline No siblings & 98.63 & 19.51 & 592 & .66 & .508 & .11 \\
\hline One or more siblings & 96.63 & $18 . .34$ & & & & \\
\hline$p<.05^{*}, p<.01^{* * *}$ &
\end{tabular}

Average problem-solving skill scores, standard deviations and t-test results of independent samples in terms of participants' number of siblings are given in Table 9. This table demonstrates that no significant differences were observed among participants' problem-solving skill scores in terms of their number of siblings $(t(592)=.66, p>.05$, Cohen's $d=.11$ ).

Table-10. T-test results of independent samples in terms of coaching/referee license

\begin{tabular}{l|l|l|l|l|l|l}
\multicolumn{8}{c}{ Table-10. T-test results of independent samples in terms of coaching/referee license } \\
\hline & M & SD & df & t & p & Cohen's d \\
\hline Yes & 97.53 & 19.45 & 592 & .76 & .450 & .06 \\
\hline NO & 96.33 & 18.25 & & & & \\
\hline$p<.05^{*}, p<.01^{*} *$
\end{tabular}

Average problem-solving skill scores, standard deviations and t-test results of independent samples in terms of participants' coaching/referee licenses are given in Table 10. This table demonstrates that no significant differences were observed among participants' problem-solving skill scores in terms of their coaching/referee licenses $(t(592)=.76, p>.05$, Cohen's $d=.06)$. 


\section{Discussion}

It was clearly demonstrated in this study that female students had significantly higher problem-solving skills compared to male students. In their study on teacher candidates, Katkat and Mizrak (2003) reported that females had better problem-solving skills compared to males. On the other hand, Tümkaya and İflazoğlu (2000) state that no significant differences were found between gender in terms of problem-solving skills. Similarly, Genç and Kalafat (2007) found out that no significant differences were observed between males and females in terms of problem-solving skills. Therefore, it can be concluded that females behave more calmly, patiently and in a more determined manner thanks to their personal traits when solving their problems in a more reasonable way.

Participants' average problem-solving skill scores in terms of universities where they study display a significant difference. It was observed that problem-solving skills of students studying at the University of The Yozgat Bozok were significantly higher compared to those studying at Erciyes University and Omer Halis Demir University. Pehlivan and Konukman (2004) demonstrated that no significant differences were observed among teachers' problem-solving skills in terms of their branches. Demirtas and Donmez (2008) too, did not find any significant differences among high school teachers' problem-solving skills in terms of their branches. Therefore, our findings in the present study overlap these studies.

Another finding of the present study is a significant difference among participants' average problem-solving skill scores in terms of their residence. In a study on students studying at school of physical education and sports, Tasgin (2004) analyzed their problem-solving skills in terms of socio-cultural differences and concluded in this study that students who came from the suburbs of the city were more sociable and outgoing. In the present study, it was found out that students who lived at a dormitory had significantly higher problem-solving skills compared to those who lived with their family or with a housemate. This can be associated with the fact that students living in a dormitory encounter problems more frequently and thus they need to find solutions to these problems by taking alternative schemes into account.

No significant differences were found among participants' problem-solving skill scores in terms of coaching/referee license and their sports branches. In a study of different sports branches, Agllonu (2014) indicated that participants' problem-solving skills had no significant differences in terms of their sports branches. In a study on football referees' problem-solving skills, Efe et al. (2008) found a significant difference between candidate and classification referees and provincial and classification referees in favour of classification referees. Altuncekic et al. (2005) argue that an individual's education process and their problem-solving experiences in this period help them use their problem-solving skills more efficiently. Therefore, it can be stated that it is possible to reach solutions more easily if an individual approaches their problems more positively.

No significant differences were observed among participants' average problem-solving skill scores in terms of their perceived economic status. Turkcapar (2007) did not find any significant differences between total problemsolving skill scores of students studying in the department of physical education and sports and their monthly incomes. Sah (2005) demonstrated that a monthly income and regular job were among factors which positively influenced problem-solving skills. It can be argued that children coming from a poor community display better psycho-motor behaviors and that students with an average or high socio-economic status overcome cognitive problems more easily thanks to various factors such as opportunity, competitiveness, and development.

In conclusion, problems bring an individual to maturity. There is no doubt that problem-solving is an indispensable life skill. Self-actualized individuals often encounter and solve problems in their lives. Therefore, an individual's problem-solving skills will positively influence their self-control and success. It can be said that positive personal traits such as creative thinking and courage turn into a behavior thanks to problem-solving skills. In this respect, we recommend adding practical courses in the curricula of the faculty of sports sciences and schools of physical education and sports in order to provide them with more opportunities for social communication and thus increase their problem-solving skills against various difficult situations.

\section{References}

Agılonu, O., 2014. Imagining athletes who play different sports branches of investigation and problem solving skills. Master's Thesis, Muğla Sıtkı Koçman University, Muğla.

Altuncekic, A., S. Yaman and O. Koray, 2005. The research on prospective teachers' self- efficacy belief level and problem solving skills. Kastamonu Education Journal, 13(1): 93-102. View at Google Scholar

Cam, S., 1995. Examination of the relationship between teacher candidates' ability to solve problems with ego situations. Turkish Psychological Counseling and Guidance Journal, 2(6): 37-42.

Cohen, J., 1992. Quantative methods in psychology: A power primer. Psychological Bulletin, 112(1): 155-159. View at Google Scholar

Cohen, L., L. Manion and K. Morrison, 2007. Research methods in education. London: Routledge.

Demirtas, H. and B. Donmez, 2008. Secondary school teachers' perceptions about their problem. Journal of the Faculty of Education, 9(16): 177-198. View at Google Scholar

Efe, M., F. Ozturk and S. Koparan, 2008. Determination of the problem solving and the assertiveness level of soccer referees in Bursa. Spormetre Journal of Physical Education and Sport Science, 6(2): 49-58. View at Google Scholar

Ferah, D., 2000. Investigation of perception of problem solving skills and problem solving approaches of the Turkish army academy cadets in terms of gender, grade, academic success and being leader. Master's Thesis, Hacettepe University, Ankara.

Field, A., 2013. Discovering statistics using IBM SPSS statistics. Los Angeles: Sage.

Genç, S. and T. Kalafat, 2007. The research on evaluation of prospective teachers' democratic attitudes and problem solving skills according as different variables. Pamukkale University Education Faculty Journal, 2(22): 10-22. View at Google Scholar

George, D. and P. Mallery, 2016. IBM SPSS statistics 23 step by step: A simple guide and reference (13th Edn.). New York: Rou tledge.

Green, S.B. and N.J. Salkind, 2014. Using SPSS for Windows and Macintosh: Analyzing and understanding data. Boston: Prentice Hall.

Güçlü, N., 2003. Problem-solving skills of high school principals. National Education 80th Year Special Issue, 160(1): 272-300. View at Google

Hayter, A.J., 1986. The maximum familywise error rate of fisher's least significant difference test. Journal of the American Statistical Association, 81(396): 1000-1004. View at Google Scholar |View at Publisher

Heppner, P.P. and C.H. Petersen, 1982. The development and implications of a personal problem-solving inventory. Journal of Counseling Psychology, 29(1): 66-75. View at Google Scholar $\mid$ View at Publisher

Ho, R., 2013. Handbook of univariate and multivariate data analysis with IBM SPSS. New York: Chapman and Hall/CRC.

Howell, D.C., 2013. Statistical methods for psychology. Belmont, CA: Wadsworth Cengage Learning.

Katkat, D. and O. Mizrak, 2003. Problem solving skills of pedagogical training of teacher candidates effect. National Education, 158(1): 7482 . 
Korkut, F., 2002. Problem solving skills of high school students. Hacettepe University Journal of Education, 22(2): 177-184. View at Google Scholar

Levin, J.R., R.C. Serlin and M.A. Seaman, 1994. A controlled, powerful multiple-comparison strategy for several situations. Psychological Bulletin, 115(1): 153-159. View at Google Scholar | View at Publisher

Pehlivan, Z. and F. Konukman, 2004. Comparison of physical education teachers and other branch teachers in terms of problem solving abilities. Spormetre Journal of Physical Education and Sport Science, 2(2): 55-60. View at Google Scholar

Pituch, K.A. and J. Stevens, 2016. Applied multivariate statistics for the social sciences, analyses with SAS AND IBM'S SPSS. New York: Routledge.

Sah, H., 2005. Investigation of the differences between physical disability and problem solving skills. Master's Thesis, Marmara University, Mersin.

Sahin, N., N.H. Sahin and P.P. Heppner, 1993. Psychometric properties of the problem solving inventory in a group of Turkish university students. Cognitive Therapy and Research, 17(4): 379-396. View at Google Scholar | View at Publisher

Soylemez, S., 2002. The study of an effect of the group program designed for the improvement of the problem solving ability in adolescence. Master's Thesis, Marmara University, İstanbul.

Tabachnick, B.G. and L.S. Fidell, 2012. Using multivariate statistics. Harlow: Pearson Education.

Tasgin, Ö., 2004. Investigation of assertiveness based on sports diversity and cultural differences of the students of physical education and sports. Atatürk University Journal of Physical Education and Sport Science, 6(4): 1-7.

Taylan, S., 1990. Adapting reliability and validity studies of Heppner's problem solving inventory. Master's Thesis, Ankara University, Ankara.

Tümkaya, S. and A. İflazoğlu, 2000. An investigation of automatic thought and problem solving levels of students in classroom teaching unit of Çukurova university according to some socio-demographic variables. Journal of Çukurova University Institure of Social Science, 6(6): 143-158. View at Google Scholar

Turkcapar, Ü., 2007. Comprasion of problem solving skills aganist stress of the students studying in the school of physical education and sport and those studying in the department of primary school teaching, faculty of education. Master's Thesis, Gazi University, Ankara.

Ulger, O.E., 2003. The relationship between leadership behaviours and problem solving abilities of school managers. Master's Thesis, Beykent University, Ankara. 